\title{
RECONFIGURACIÓN DEL SUJETO INSUMISO EN LA NUEVA NORMALIDAD. MIRAR NO ES OBSERVAR
}

\author{
Robinson Salazar Pérez* \\ https://orcid.org/0000-0003-0787-6876
}

RECIBIDO: Octubre 2020 / ACEPTADO: Noviembre 2020 / PUBLICADO: Enero 2021

\begin{abstract}
Como citar: Salazar Pérez, Robinson. (2021). Reconfiguración del sujeto insumiso en la nueva normalidad. Mirar no es observar. Telos: revista de Estudios Interdisciplinarios en Ciencias Sociales, 23 (1), Venezuela. (Pp. 116-128).

DOI: www.doi.org/10.36390/telos231.09
\end{abstract}

\section{RESUMEN}

La presente reflexión escrita lleva la intención y contenido de explicar la alternativa escogida por el sujeto insumiso ante la Nueva Normalidad. Parte de la premisa argumentada de la existencia de un nuevo espectro social caracterizado por la diversidad cultural, amplio mapa ideológico, diferentes demandas sociales y la imperiosa necesidad de articular fuerzas en un arco convergente. La idea fuerza es sin lugar a dudas la articulación, concepto que definimos y describimos la forma en que debe darse para una acción política de insumisión con la voluntad de todos los colectivos populares. Es claro y así está reseñado, la magnitud del desafío es significativa y encomiable, dado que es impostergable desaprender aprendiendo en el quehacer de la política con perfil transformadora, porque la herencia neoliberal expresada en el individualismo, narcisismo, destrucción de comunidades y aldeas, estragos en los imaginarios colectivos y rituales que dan forma al entramado y lazos sociales deben ser re-armados para dar cuerpo a la nueva lucha. Si la globalización tuvo como fin destruir comunidades y diseñar el individualismo consumidor, la reconfiguración del sujeto insumiso transita por re-lanzar la lucha desde lo comunal a fin de resarcir los hilos asociativos de la densa red de las comunidades.

Palabras claves: Sujeto colectivo; Nueva Normalidad; Individualismo; localidad; insumisión.

Reconfiguration of the subject under the new normality. Looking is not observing

\section{ABSTRACT}

Latin America once again defies the history at crucial moments when the New International Order aims to establish a New Normality. The present reflection has the intention and content of explaining the alternative chosen by the unsubmissive subject in face of the New Normality. Part of argued premise about the existence of a new social spectrum characterized by cultural diversity, a broad ideological map, different social request and the urgent need to articulate forces in a convergent arc. The main idea is without any doubt the articulation, concept in which we define and describe the way in which it should be given for a political action of unsubmissition

\footnotetext{
* Universidad Autónoma de Sinaloa/México. Director de www.insumisos.com. Correo electrónico: salazar.robinson@gmail.com
} 
with the will of all popular collective. It is clear and thus it is outlined, the magnitude of the challenge is significant and commendable, since it is urgent to unlearn and learning in the political work with a transforming profile, because the neoliberal heritage expressed in individualism, narcissism, destruction of communities and villages, havoc on collective imaginaries and rituals that shape the framework and social link, they must be re-armed to give shape to the new struggle. If globalization was aimed at destroying communities and designing consumer individualism, the reconfiguration of the unsubmissive subject transits by re-launching the struggle from the communal in order to compensate the associative threads of the dense network of communities.

Keywords: Collective subject; New Normality; Individualism; locality; unsubmission.

"El futuro está en lo local, en los circuitos cortos, en el renacimiento de las comunidades, en la democracia directa, en el abandono de los valores mercantiles.

El antídoto será encontrado cuando los ciudadanos descubran

que no son sólo consumidores y que la vida puede ser más bella si repudiamos un mundo donde nada tiene valor, pero todo tiene un precio" Alain de Benoist/ CONTRA EL LIBERALISMO y POR LA LIBERTAD 06 de noviembre de 2020

\section{Contexto social}

\section{En la Nueva Normalidad hay que re-politizar para avanzar}

La sociedad contemporánea latinoamericana, rasgada de sus vestiduras por la pandemia, nos revela aristas interesantes y necesarias para reflexionar sobre qué espectro social tenemos, de qué manera poder ejercitar la libertad y la democracia en un escenario de disciplinamiento social devenido de un virus creado para reordenar el mundo.

De aquella mirada ortodoxa y clasista de los años 80 del Siglo $\mathrm{XX}$, donde tres segmentos significativos estaban ante nuestras observaciones, Ricos, Clase Media y Pobres, fue diluyéndose al pasar a la lente prismática del Siglo XXI, cuya diversidad nos tocó las distintas ventana del cerebro para fijar la atención en el nuevo mapa actoral en aparición, el cual daba forma a la sociedad de Nuestra América.

Hoy el arcoíris de comportamientos, ideas y hábitos es diverso, tanto o igual como la cantidad de grupos humanos que conviven y comparten un mismo espacio. Existen particularidades de origen, género, edad, orientación sexual, funcionalidad cognitivas, habilidades específicas, emocionales, físicas para el trabajo, los estudios o en formas de participación social.

Ante una cartografía humana compleja, producto de la evolución de nuestras sociedades, la ramificación de actividades diversas y complejidad de relaciones de distintos tipos, los seres humanos van adaptándose a cada uno de los nuevos escaques aflorados, producto de las nuevas tecnologías, expansión territorial, amalgamas de culturas y expansión de ciudades y otros factores imposible de mencionar por ser casi ilimitados.

Obviamente, un factor preponderante en el reconocimiento y acciones de defensa de la diversidad es la globalización, a través de internet, el intercambio de información, la 
transferencia de saberes, conocimientos, cúmulo infinito de contactos y de relaciones virtuales, abrieron un horizonte al interior de los espectros sociales, dando formas a comportamientos estigmatizados en sitios o localidades, otros obtuvieron experiencias mediantes crónicas y relatos de temas y asuntos de su competencia y similares a las suyas, ahí abrevaron para discernir mejor sobre su condición, entender que no eran casos de excepción, en otras latitudes hallaron semejanzas y de esta manera descubrían su particularidad dentro de un concierto social diverso. Además, se dan cuenta de algo importante para ellos, "siempre han sido distintos. Lo que se ha estrechado es nuestra idea de diversidad y la función que cumple en las democracias" (Malik, 2017).

En algunos lugares de América Latina, aún persisten quienes retoman algunos criterios para clasificar y asignar las diferencias desde la perspectiva de la raza, ideas incubadas y abrigadas en el Siglo XIX; otros más aferrados están inscritos en el enfoque clasista del Siglo $X X$, todos ellos ajustan los lineamientos de democracia en el cálculo de la ventaja y la ganancia, o sea, mayorías y minorías, sin distinguir las particularidades en cada contingente percibidos por ellos e inscritos en la esfera política.

Tal vez, en la visión clasista exista un temor, aceptar la diversidad puede conllevar a traicionar la utopía de las organizaciones y partidos políticos, no obstante existe la salida de la "traición" a partir de una figura analítica: la articulación de la diversidad con propósitos políticos, esto es, la manera de construir la urdimbre necesaria con previos acuerdos de demandas, actuaciones escalonadas en espacios autónomos y estratégicos, los cuales posibiliten la reproducción de la acción colectiva de perfil netamente político sin tropiezos significativos entorpecedores de la cualificación de lucha reivindicativa.

Entremos en materia de dar a conocer la articulación política de diversos actores involucrados en la confrontación contra el estado de cosas vigentes.

\section{Articulación Política para una democracia del siglo XXI}

Si tomamos como punto de partida al sujeto político, en los años 90 del Siglo XX aún era una construcción sin embargo denotaba en su trayectoria y actuaciones públicas no devenidas de un solo segmento social definido, su composición y organicidad tenía componentes heterogéneos, amalgamientos de movimientos de género, campesinos, indígenas, obreros, gremialistas, sin tierra, sin techo, cocaleros, estudiantiles, precaristas, jubilados, pensionados, buhoneros entre otros), eso sí, trazaba una clara tendencia incremental en su cuerpo semi estructurado.

Lo definimos así, porque sólo revela o hace notorio la organicidad portada al momento de sus actuaciones en las plazas públicas, en las protestas, asambleas, corte de rutas, movilizaciones, toma de calles y en los escenario donde se dirimen asuntos públicos propios de los reclamos de derechos cancelados o con cuestiones del poder, pero en un breve lapso, regresa a su estado natural o de latencia, diseminado, inorgánico y actuando en el campo la vida cotidiana de cada miembro o en otras ocasiones, recuperando su autonomía de sujeto (en el movimiento en que está inscrito) después de haber participado en una acción convergente, ello en caso de ser un gremio con mayor antigüedad, con herencia y caja de herramientas curtidas en anteriores periodos y en esos momentos de recogimiento acuden a sus antiguos espacios donde retroalimentan sus experiencias a través de la autocrítica y balances de las recientes movilizaciones. 
Con los tropiezos y equivocaciones, principalmente la subordinación bajo la férula de los gobiernos "progresistas", donde cedieron pasivamente en cuanto aplazaron demandas, prestaron su organicidad en impulsar reformas de gobierno, sus movilizaciones no tomaron distancia de la autoridad, los espacios construidos y con algún grado de autonomía fueron desmembrados al permitir insertar propósitos gubernamentales en asuntos y tareas propias del movimiento, las fronteras adquirieron porosidad y las aguas del poder fueron inundando poco a poco la especificidad y autonomía del sujeto político.

Por ello, la derrota de los "progresistas" arrastró a los sujetos colectivos populares, la brújula de gobierno anclada en el imaginario de los militantes, al momento de perder el gobierno, consubstancialmente arrojó a la oquedad a los actores políticos, descobijados en sus recursos al ser dependientes del dinero y plataformas proporcionadas por los agentes gubernamentales.

Hubo la necesidad de re-comenzar a reconfigurar su estado orgánico, armar las demandas en función de la circunstancia impuestas; las herramientas de lucha, la caja de la memoria colectiva tuvieron de nueva cuenta el reto de renovarse, identificar a los otros con quienes poder trazar alianzas, observar detenidamente las nuevas estrategias del enemigo, desmontar la fuerza aplanadora de los medios de comunicación a través de la construcción de nodos y redes sociales, insertar los reclamos justos con inusitada resonancia en la sociedad excluida, revisar la agenda de movilizaciones y retomar la experiencia de no entregar su capacidad ni estructura a un gobierno aunque éste esgrima y demuestre posturas de corte popular. Acompañar y defender no es subordinarse porque al final el sujeto político es quien debe delinear y construir la ruta hacia la búsqueda de la utopía emancipatoria.

Entonces llegó la hora de articular al sujeto histórico posibilitador de una transformación que los lleve a avanzar significativamente; no es la oportunidad de emancipar totalmente los escaques controlados por la derecha, sino de romper, desestructurar, fisurar parte de la hegemonía impuesta.

Es imprescindible entender la naturaleza, capacidad, habilidad y condición del sujeto para producir y re-producirse así mismo. Su comportamiento marcará la ruta y curso de la historia; es más, no existe esta última fuera del sujeto o al margen de este, como tampoco se da un sujeto sin historia.

"Este sujeto, visto como hacedor de historia es una abstracción indeterminada que se historiza propiamente en el de un sentido totalmente determinado por su intencionalidad. Cuando hablamos de sujeto histórico en el sentido relativo de la política es entendido como una articulación de sujetos específicos, cuya especificidad está dada por condiciones objetivas no elegidas por ellos y constituyen condición necesaria de su articulación. Al articularse ponen en vías de efectualización un proyecto"(Pérez Lara, 2000. S/P).

El sujeto político en insumisión adquiere una naturaleza de movilización continua, actualización de herramientas de lucha, recupera experiencias y las engarzar con propósitos actuales, abre espacios de interlocución con otros actores insertos en la realidad en proceso de reproducción, encaja objetivos de lucha, valora estrategias de resistencia, busca convenir las formas de ocupación de espacios estratégicos habilitados para sembrar demandas y atraer a los auto convocados, todo ello con la finalidad de aglutinar otras fuerzas 0 actores, porque la 
cualidad y naturaleza del sujeto en insumisión va construyéndose día a día al reconocer su organicidad, particularidad y esencia no homogénea.

Su atributo es resultado de la diversidad propia de la sociedad contemporánea, resultado de la complejidad de distintos tipos de signos, cuadros simbólicos, valores y trayectorias devenida de la pluriculturalidad, y todos ellos confluyen temporal, parcialmente en un proyecto que no puede verse de manera absoluta, sino entender los condicionamientos impuestos por la dinámica de la propia realidad y de la cual somos parte de ella.

Intentar armonizar ideales no es asunto mecánico, en la suma de demandas hay cierta carga significativa de emociones, cada grupo o sector la defiende porque ancla en ella su identidad, el factor significante de la particularidad de lucha e inserción en el mapa de la política contestataria. Entonces los arreglos entre segmentos políticos en insumisión es materia compleja referente a la forma de dialogar, armar y tejer las exigencias sin que pierdan su identidad y significante de lucha, ello conlleva a construir un amplio mapa de actuaciones públicas, definir espacios en dónde sembrar el reclamo y protesta, en qué momento conjuntar esfuerzo de movilización mayúscula y cuándo deben actuar las demandas específicas sin desabrigar su acción reclamante en las movilizaciones.

En la rebelión de carácter general, esto es, cuando abordan una movilización amplia, plural, con objetivos concretos, para señalar con ejemplos, actuaciones colectivas masivas por derogar un Estado de sitio, alguna ley oprobiosa y lacerante, destituir un gobernante o impedir una actuación lesiva a la mayoría de la sociedad, cada segmento o colectivo se (des)constituye de su forma particular y su perfil significante lo pone al servicio del colectivo Insumiso, funciona como un bucle, en cada etapa de confrontación, es singular en su demanda propia y es colectiva en la suma de insubordinación total, zaguán necesario para avanzar en la ruta de las reivindicaciones significativas.

Insistimos, en la articulación hacia la condición de insumisión no es posible acudir al cálculo de la ventaja y la ganancia, o sea, las mayorías someten a las minorías, ello conlleva a negar, por un lado, el espacio construido con tramas sociales de años, donde cada actor ha fabricado una urdimbre social donde ha anidado sus propias formas de organización y expresión social y política.

Retomando parte de las ideas de Pérez Lara (2000), Estructurar la alianza insumisa pasa por el tamiz se sumar estas formas particulares de organización con la noción y proyecto de insumisión, siempre teniendo en cuenta la idea fuerza de que construyamos un encuentro constructivo, de conocimiento y aprendizaje mutuo. Son los propios actores los indicados para configurar los caracteres específicos de ese nuevo tejido aliancista con atributo de articulación de las diversas expresiones del tejido social particular o micro sociales.

Armonizar en el espectro de la diversidad no implica despolitizar ni negar el tinte ideológico de cada segmento organizado partícipe en la construcción de la insumisión por transformar una parte significativa de la realidad social. Es innegable la existencia de aferramientos valóricos, algunos frenan e impiden muchas veces concertar sobre estos temas de trascendencia, de ahí la necesidad de borrar de nuestro imaginario la tradicional idea prevaleciente en la política aliancista o de coalición: "convenir es ceder o perder", prejuicio legendario inoculado en el inconsciente colectivo de gran parte de los colectivos populares.

El mayor énfasis debe afianzarse en la explicación razonada de la valía intrínseca de la diversidad, la cual debe ser percibida, aceptada y defendida como un bien social, cuya 
esencia nos orienta a darle el valor significativo a los segmentos orgánicos pequeños, inyectándoles en el imaginario el mérito e importancia de su participación en el concierto de la insumisión, todos los gremios e instancias orgánicas de la política cuenta con el peso y la representación equitativa, voto y decisión al igual que las otras, por ello sus demandas serán valoradas, analizadas e incorporadas de acuerdo con el momento y carácter de lucha.

Ahora bien, en la construcción del sujeto insumiso es importante reconocer el valor intrínseco de la diversidad, porque la esencia y condición del sujeto en mención es producto de ella, de ahí la ineludible tarea de aceptarla, asumirla y ejercitarla en la pluralidad de voces es un ejercicio irrefutable de coherencia con la sociedad contemporánea, un acto acorde a la realidad social y en consonancia con el arcoíris de pensamiento existente.

Es de gran trascendencia reconocer y aceptar el protagonismo de la diversidad política y cultural que portan y revelan el mundo de las movilizaciones populares; también comprender la impotencia guardada y sus actitudes irritantes ilustradas en sus discursos, las cuales son producto de la exclusión, marginación y represión recibidas durante largos años; sus actuaciones violentas algunas veces denotan la búsqueda por saltar el cerco, romper el aislamiento, re-situarse en el espacio público y salir de los espacios vigilados y renegados desde las esferas gubernamentales.

Entonces,

"la participación inclusiva requiere medidas y mecanismos explícitos que aseguren la integración de la diversidad de opiniones e identidades a los procesos y a las medidas políticas. Asimismo, estas opiniones deben respetarse y divulgarse a través de otros grupos sociales y se traduzcan en acciones y políticas que garanticen estas medidas, además incorporen en las demandas respeto, tolerancia apoyo al pluralismo jurídico y las cuotas de participación política." (El-Kholy,2013 $\mathrm{s} / \mathrm{p})$

Finalmente, para situarnos en disposición de insumisión requerimos integrar a todos los segmentos orgánicos de la sociedad en la idea de actuar en un solo frente colectivo con la firme y clara tarea de emancipar o romper una parte del sistema de sometimiento impuesto. Sólo de esta manera es posible cambiar el discurso politizado particular y sustituirlo por otro acorde a la diversidad, refleje la lucha común, el interés de toda la colectividad, integrando vanguardia horizontal con capacidad analítica y discurso inclusivo para armar el arco convergente y las estrategias de mediano y largo plazo las cuales vayan retroalimentando al sujeto insumisos en cada actuación llevada a cabo.

\section{Desarmar para re-armar}

En los años del período neoliberal, la derecha construyó la estrategia de Guerra Cultural de mayor envergadura, la cual supeditó la confrontación, invasiones e intervenciones directas a un segundo lugar. La esencia de la confrontación cultural tuvo su centro de atención desdibujar los imaginarios colectivo populares, inocular el pensamiento de las mayorías con mensajes incentivadores hacia el éxito sin tener que recorrer largo camino de esfuerzo y trabajo, la inmediatez era y sigue siendo signo de logro, la individualización coadyuva a destacar obtener singularidad y sobresalir ante su entorno inmediato; la construcción social de la realidad no era canalizada a través de los sentidos y filtrada por el tamiz de la reflexión o diálogo con otros, sino 
a través de los dispositivos electrónicos de comunicación expedita, domesticaron a la inteligencia, maniataron la creatividad, sometieron la inquietud e inteligencia y secuestraron la imaginación.

La mediación electrónica digital fue remplazando las relaciones intersubjetiva, los lazos sociales, la capacidad dialógica y construcción de espacios de re-encuentro donde germina y florecen el tejido social y reproducción social de la sociedad.

Los mensajes de la mercadotecnia, el consumo, la política del "progreso", el ideal del éxito fue canalizada hacia un imaginario del desecho, nada es necesario mantenerse porque lo clásico es "Vintage" pero nunca marca el paso de lo novedoso. Innovar es cambiar en cada momento que transcurra menor a un año, ayer es pasado lejano, mañana es materia ausente en el pensamiento y mejor prolongan el presente sin horario ni calendario.

Todo este arsenal de mensajes finamente elaborado por los think tank conservadores fue situado en los medios escolares, Televisión, internet y en grupos financiados en Youtube, Facebook, TikTok, entre otras redes para alienar a la población menor de 40 años y dirigirlas al entrenamiento de aprender a ocultar la realidad o entorno social y ofrecerles a cambio un ideal de "prestigio", visibilidad, like y menciones manipuladas a través de bots o algoritmos elaborados para para inflar un personaje, cantante 0 artista que forman parte de las constelaciones y financiamientos de las redes del poder económico.

Ellos, la derecha, dirigieron su arsenal de herramientas políticas a todos aquellos signos, objetos, seres humanos o propaganda reveladora de un viso anti-neoliberal, de ahí que las organizaciones, agentes y actores con perfil notorio...

"El Foro de Sao Paolo y el Grupo de Puebla entre otros, son blancos de críticas porque intentan socavar los elementos más básicos de las democracias liberales, como la separación de poderes, el estado de derecho, la propiedad privada, la libertad de expresión. Si entras en la página del Grupo de Puebla están las firmas de Fernando Correa, Lula da Silva, Evo Morales, pero también las de Irene Montero, José Luis Rodríguez Zapatero o Baltasar Garzón"(Martín Frías, 2020,s/p).

El objetivo es claro, dotar de musculatura intelectual para tratar de armar partidos mayoritarios del conservadurismo en todo el planeta. La tarea de reorganizar para luchar es remontar la montaña más alta de todas las luchas reivindicativas que América Latina ha confrontado en los últimos 3 siglos. Un primer paso sería ir dibujando el escenario caótico existente y de alguna manera hallar las fisuras para recomponer el mapa social adecuado para un re-impulso de lo popular desde abajo.

\section{A/Recomponer el trabajo comunitario o comunal}

Un segmento deteriorado es el lazo social, el cual está cargado de desconfianza y competencias por desplazar al otro. Tuvo su génesis en la inserción de la idea de lo global, cuyo eje principal fue desaparecer del imaginario social popular la existencia de construir comunidad 0 aldea, porque la singularidad no cabía en la homogeneidad global.

Para romper las fronteras de las comunidades territoriales las remplazó con las ideas de comunidad virtual, cuyo oficio y objetivo es propio del mercado: vender, trabajar, comprar y vivir en una virtualidad o aldea imaginaria sin diálogo pero cargada de signos. 
Fue una descomunalización paulatina, con diversos difusores para inundar la amplia capilaridad social, el fundamento eje tuvo fuerza en enarbolar al individuo al cual lo dotó de una capacidad inusitada para competir en contra de los suyos; el otro ya no fue percibido como aliado sino un agente peligroso que aspiraba a apropiarse de tu espacio, oportunidades, deseos y ambiciones. Obviamente la singularidad en una comunidad no ayuda a reproducir hilos asociativos, antes por el contrario, rompe, fisura y siembra desconfianza, alienta el autoritarismo, reproduce las jerarquías de fuerza y poder llevando finalmente a reforzar el imaginario patriarcal que hoy es base de todo fundamento de la derecha en el Siglo XXI.

\section{B/ Desconstruir la individuación}

Otro promotor de la fatídica individuación estuvo en alentar la hiperculturalidad caracterizada por crear un gran mercado de cultura única, un abrevadero uniforme para todos, cancelando la particularidad y forjando una red donde vinculaba en cuerpo y pensamiento a la población mediados por las redes virtuales y dispositivos electrónicos.

Si tratamos de ver la linealidad de la red detectamos una tendencia asintótica, infinita, la misma atrae a los usuarios y los envuelve en torbellino sin territorio ni pertenencia, es un espiral que va despojando a los visitantes de su sentido, los involucra en un afán de ser parte de algo inexistente, entonces cae en el precipicio de vivir una sucesión de presentes, con una carga enorme de cadenas de emociones efímeras donde lo nuevo lo apasiona, lo consume y y hace de ello el mejor diseño de su personalidad narcisista. Obviamente el narciso no busca asociación porque su ego lo lleva a competir para excluir a los otros.

Su vínculo comunicacional es consigo mismo, se asoman a las redes y exhiben prendas de vestir, alimentos, autos, viajes, bisutería, fiestas entre otras insignificancias, todo bajo la férula de promocionar el Yo, lo amplifican, invitan a que le otorguen un like para revitalizar su rendimiento como "sujeto light" en la ola emotiva del mundo de las redes sociales.

Es una "hipercomunicación con sesgos paradójicos donde sólo establece contactos pero destruye las relaciones, a su vez elimina la distancia, pero al mismo tiempo destruye la cercanía y la amistad" (Chul Han- Byung, 2020).

\section{$\mathrm{Cl}$ Mitos y ritos para la recuperación de la memoria}

Comunidades sin rituales ni ritos, desbocadas a negar la memoria, en tanto el consumo excesivo de las cosas conlleva a desgastarlas pero no a repararlas. Nada es perdurable, todo es posible remplazarlo por otra cosa igual o mejor, es la carrera por producir sin importar la duración. El tiempo en esta sucesión de hechos pierde significancia, lo creado por ellos no es para siempre, tampoco tiene unos antecedentes ni lo produzco para mañana. Todo lo nuevo es para consumirse y al momento de ser producido pierde su interés para el creador

Entonces observamos que hoy nada dura, nada persiste. Este carácter efímero actúa sobre el individuo, lo desestabiliza, lo hace perder las certezas. Es precisamente esta incertidumbre, este miedo por uno mismo lo que conduce al funcionamiento "vacío" del ego (Chul Han-Byung, 2020).

La memoria colectiva anidada en la aldea fue difuminada, los recuerdos, las festividades, los aniversarios, los tiempos de las etapas vitales de la vida, los umbrales narrativos que delimitaban las fronteras de un acontecimiento, edad o proceso fueron olvidados, el 
individuo fue desterrado de su localidad y lo sembraron en la red de traslados vertiginosos, yendo de un lugar a otro como si fuese una mercancía (Álvarez Teran,2020).

Sin espacio para re-crearse, vínculos sociales tronchados, lazos sociales sin dosis afectiva, insertos en una sociedad carente de diálogo para reproducir discursos, ideas, intercambiar conjeturas y edificar razonamientos propicios para comprender la realidad social, dan pie a fraguar un espectro social cargado de incertidumbre, la gran mayoría de la población no percibe la seguridad en todas sus acepciones, los temores arropan el imaginario, el pensamiento se cubre de obnubilaciones y ven en los otros los posible o potenciales agresores. Justo en el mar de miedos y confusiones emergen los padecimientos de ansiedad, la inseguridad para crear horizonte dibuja de antemano el fracaso y lo coloca en la bandeja cercana de su imaginación cotidiana y la sociedad de la angustia va engullendo al sujeto neoliberal.

Parafraseando las reflexiones escritas de un sociólogo francés, podíamos resaltar lo notorio e indiscutible de los efectos de la individualización, cuya expresión ha roto los encuadramientos colectivos. En años anteriores a la globalización cada uno de nosotros pertenecía a un colectivo de trabajo, de barrio, de religión, equipo de deporte o club de amigos. Este domo de colectividad dotaba de certeza y sostenía a los individuos que vivían en condiciones difíciles, recibían del nácelo grupal una suerte de seguridad interior. En la actualidad podríamos afirmar que poseemos libertad para cambiar de oficio, mujer, religión, lugar de residencia, automóvil, incluso la vida privada es más libre, pero los individuos son extremadamente frágiles, lo observamos con los intentos de suicidio, el estrés, las depresiones, las adicciones, los intento de fuga sin cambiar de lugar, en fin, una fragilización de la vida individual que nos lleva o conduce a vivir en un mundo problemático ...esta sociedad ha permitido más libertades, pero esa autonomía individual tiene un precio fuerte, que es la fragilidad psíquica (Lipovetsky,2020 s/p).

Obviamente, no hay que condenar al conjunto de la sociedad, sino de nuevo enriquecerla, modificarla substancialmente desde sus centros culturales, en el retoño comunitario, en la localidad donde habitan, trabajan o se re-crean los sujetos adormecidos.

Para cambiar no es imperioso esperar una crisis mayor a la forjada por la pandemia y la Nueva Normalidad, tampoco se den las condiciones para una toma de conciencia en todos los actores afectados; es hora de actuar y re-trabajar la política de la insumisión a partir del saldo dejado por los estragos del vendaval neoliberal.

Es hora de Inocular territorios, barrios, veredas, brechas habitadas, centros educativos, localidades de diversos tipos y modelos para restaurar el andamiaje de la confianza, cargar de contenido los diálogos, acompañar cada observación en miradas colectivas, diseñar ideales de trabajo, colaboración y reciprocidades, desentrañar la solidaridad de sus estertores, admitir que la unión de los desposeídos nace del saldo de las diferencias y justo ahí, desde ese remanente comenzar a edificar una novedosa forma de organización para la lucha futura.

\section{Relocalizar al Sujeto Insumiso}

Retomar el camino de hacer política desde lo local es una recuperación del ejercicio militante que tuvo grandes avances y éxitos en los años 60 y 70 del Siglo XX. Aún permanecen los sedimentos del trabajo ejercitado en los sujetos colectivos populares en países con tradición 
de lucha y movilizaciones de resonancia, grupos alzados en armas y gestas de liberación, entre ellos Colombia, Perú, Nicaragua, El Salvador y Guatemala para mencionar algunos.

Obviamente, hoy poseemos mayores recursos teóricos, experiencias sistematizadas, acompañamientos analíticos de intelectuales orgánicos 0 críticos, caja de herramientas más sofisticadas, controles de algunos espacios autónomos con disponibilidad de ser estratégicos en la lucha, alianzas inter-gremiales, mayor curtido en las confrontaciones y una memoria colectiva para habilitar en cada episodio de conflictos.

Anteriormente la inserción en lo local era una tarea con signos de aventura, fue la prueba de una militancia desafiante por sembrar la semilla de la insumisión sin contar con experiencia alguna o destrezas comunicacionales para atraer la atención de personas o grupos humanos agobiados por la pobreza y la represión.

Iniciaba con anclar a un militante en un poblado, localidad o comunidad seleccionada y a la vez el lugar posibilitara ampliar radio de acción política partidaria, avituallamiento en caso de grupo rebelde, conexión entre dos o tres zonas para transitar o vacío de militancia donde ameritaba incorporar nuevos elementos

El punto de partida era reconocer el lugar, observar las tramas sociales de los habitantes, movilidad laboral, tipo de trabajo, liderazgo existente y características del mismo, narrativas comunes dentro del poblado, temas torales que atraían su atención y a partir de ese mapa socio-político rudimentario, iniciaban las diversas tácticas de acercamiento, principalmente en fraguar la confianza.

El punto de partida de construcción de la confianza era saber confeccionar una pieza discursiva llana, la cual recogiera las inquietudes, las carencias, anhelos, deseos y esperanzas de la aldea. Identificar los obstáculos de tipo social, naturales, políticos y organizativos que estaban presentes e impedían en gran parte plasmar esas aspiraciones colectivas. Una vez armada la alocución y purgada de signos políticos partidarios fácilmente identificables, hacían una apuesta hecha en el presente con miras al futuro, sin desdeñar las experiencias del pasado, algunas de ellas fueron engañosas o vitales para la colectividad.

El balance elaborado a través de la participación de la pluralidad de voces residentes del poblado, es la olla donde van depositando cada uno la confianza, misma la cual dotará de certidumbre las acciones a emprender en el futuro.

Hoy la inserción política en lo local cuanta con mayores recursos y comprensión de lo que significa el trabajo de organización de los sujetos colectivos.

En primera instancia, existe un mapa concurrido de organizaciones en cada localidad, desde barrios, pasando por veredas, aldeas, parroquias y pueblos, quienes han dotado de organicidad sus reclamos, demandas y luchas ante el despojo, el olvido, la violencia y defensa de sus recursos. Anclar un trabajo de coadyuvancia no parte de cero, mucho menos tendrían que repetir las peripecias de los años 60/70 del Siglo XX. Esta vez la inserción es de acompañamiento inteligente, interpretador de los acontecimientos, esclarecimiento de dudas en caso de la existencia de una disyuntiva en momentos cruciales para la toma de decisiones, auxiliar en dibujar escenarios de riesgos, cooperar en casos de elaborar documentos o fijar postura en mesa de negociación, cuidar los riesgos de las decisiones para evitar en estas las interpretaciones ambivalentes y dotar de certeza discursiva en situaciones de agobio 0 presiones externas. 
Es significativo resaltar el requerimiento que tiene hoy el territorio, la aldea o localidad, cuyo eje principal es incorporar la apropiación del espacio por las diversas acción social llevadas a cabo por los numerosos colectivos, con la particularidad de existir un "juego de poder" entre los sujetos actuantes en el espacio.

En ese "juego de poder" van definiéndose la identidad relacionada con un espacio determinado. El territorio es una apropiación física y simbólica donde cada habitante hace suyo el lugar, lo dota de sentido, lo asume como suyo en cuanto de ese suelo adopta un gentilicio, una forma de ser genérica, los relatos y mitos son parte de su imaginario y las narrativas son parte de su lenguaje cotidiano y particularidad para diferenciarse de otros lugares.

He aquí el por qué es concebido sociológicamente como un largo proceso de construcción social. En el pasado hubo destierro, persecuciones, desplazados por la violencia y el despojo, no obstante el sujeto colectivo retornaba y/o vivía añorando su regreso, habitaba un lugar ajeno sin que le concedieran un espacio de reproducción social, hoy lo entendemos porque el conjunto de relaciones sociales reproducidas en su tierra originaria lo dotó de un sentimiento de pertenencia, fortaleciéndose con el tiempo y encadenándose con los lazos sociales creados de naturaleza solidaria, reciprocidad y respeto ante las diferencias.

El saber distinguir la naturaleza de la sapiencia territorial producida y aprehendida por el conjunto de habitantes de un pueblo, es un aspecto primordial para observar y participar en un ejercicio político que conlleve a recomunalizar la insumisión. Es necesario aclarar, muchas veces rebelarse o desobedecer no destina necesariamente a cambiar drásticamente la realidad social cuestionada. Desobedecer una norma, un conjunto de iniciativas coercitivas o agraviosas para con el pueblo es una acción política de insumisión en cuanto rompe la lógica de imposición, desdibuja el ejercicio del poder autoritario, invalida un hecho actuación denigrante, detiene una intervención de ultraje y revela el músculo de un sujeto colectivo para defender su espacio y libertad.

Las protestas son expresión de desobediencia orientadas a construir espacios estratégicos de lucha, no sólo para la denuncia, sino fincar y visibilizar una demanda. Para obtener mejores resultados es necesario salir a las calles o espacios públicos teniendo en cuenta las condiciones políticas prevaleciente, si eres fácil presa de la represión o eliminación. Lo súbito, el control del espacio y las herramientas de defensa son indispensables en situaciones de pandemia/miedos/represión.

Visto así, las protestas como acciones para construir espacios estratégicos de lucha, no sólo debe quedar en la denuncia, sino en atraer otros sujetos inconformes, encadenar demandas, enviar señal de apertura para otros colectivos políticos y el diseño y visibilización de la protesta sea en lugares estratégicos para resaltarla sobre todos los actos llamativos.

Hay que tener claridad en acontecimientos comunes en la amplia territorialidad latinoamericana, donde la llegada de gobiernos con sesgo popular arriba al poder con la participación significativa de un conjunto de ideas, movilizaciones y demandas incorporadas ni atendidas por la presidencia. Es justo ahí donde se marca la distancia entre la retórica popular y la acción de insumisión, porque en las administraciones "progresistas" fue evidente el uso y abuso de los gobiernos hacia la participación popular, la cual fue relegada a ser correa de trasmisión de políticas gubernamentales y desatención de sus demandas, lo cual conllevo a un deterioro de su organicidad y enturbiamiento de sus ideales ante los miembros del colectivo 
Ahora bien, desde lo local y con las estructuras socio-políticas existentes en diversos lugares, es de mayor efectividad anclar una estrategia que pase de la resistencia a las reivindicaciones, debido a las condiciones de prevalecientes en la denominada Nueva Normalidad.

Al existir un factor preponderante de dominio y control sobre todos como lo revela la pandemia y el uso de ella por parte de los gobiernos, percibimos que lo adecuado y optimo no es tener como idea fuerza la acentuación al interior de la organización la distinciones ideológicas, tampoco diseñar ni tomar decisiones bajo la consigna de mayoría Vs minorías.

Evitar bajo todas las formas y esquemas la configuración de partidos emblemáticos únicos, esa rémora es negación de la diversidad y autocrítica y por tanto condenadas al fracaso.

El partido único y liderazgo compulsivo es un fenómeno de aferramiento de personajes embelesados en la adulación y repiten años en la dirección y gobierno, ciegos ante la realidad que los rodea y mirando a través de la obsecuencia de sus leales colaboradores cercanos.

Llego el momento de abrir una etapa de la diversidad, ese concepto politizado implica diversos en lo sexual, raza, intereses colectivos y comunitarios, territorial, valórico, miscelánea ideológica sin apropiación segmentada, "articulación de saberes y experiencias de lucha, representación con participación, frente de lucha en vez de partido, conjunción molecular" (Salazar,2003), una izquierda tolerante, incorporadora, flexible, no ortodoxa y de convergencia de diversidad de ideas, propósitos y satisfactores sociales.

Aun oreamos en el mapa latinoamericanos casos singulares de liderazgos compulsivos, algunos reciben apoyo y piezas escritas de intelectuales que no andan ni desandan los senderos de las luchas locales y/o comunitarias; desde el cómodo escritorio refieren las gestas de los colectivos populares a través de un nombre propio, "líder" que no cuenta con apoyo porque al momento que arribó al poder fue cobijado con las luchas, movilizaciones y demandas de los sujetos políticos populares pero al abordar el gobierno olvidaron el compromiso y administran el equilibrio de la llamada gobernabilidad.

Ejemplos de ese tipo lo vivió América Latina con la llamada etapa "progresista"; hoy de nueva cuenta algunos países retoman el sendero de resarcir los errores, apoyan a candidatos sin antecedentes de liderazgos compulsivos, esta vez para demostrar que no es el personaje candidato, el nombre propio o quien encabeza la boleta electoral. Son los de abajo, los colectivos populares, las movilizaciones nacidas de las aldeas y localidades los que muestran músculo de reivindicación, paso firme para dejar atrás la resistencia y llegar al plano de proponer, medir fuerzas y plasmar ideales.

No hay dudas, los líderes compulsivos buscan intersticios para sembrar su figura pero la historia es como el fuego, purifica cuanto toca.

\section{Referencias Bibliográficas}

Alvarez Teran, Claudio, (2020). La Desaparición de los Rituales, extraído de https://www.youtube.com/watch?v=rlWn-tglAfY

Chul Han- Byung, (2020). "El narcisismo actual se basa en el vacío" extraído de https://www.bloghemia.com/2020/11/byung-chul-han-el-narcisismo-actual-

se.html?fbclid=IwAROfHUNb-

WQ6KEecKHdRozrgjGsqfaNy8sORbxQVvGI8Z2Y4f2t3i3nUBus 
El-Kholy, Heba. (2013) Sin diversidad, no hay democracia. Programa de las Naciones Unidas para el Desarrollo; Objetivos de desarrollo sostenible, PNUD, Extraído de https://www.undp.org/content/undp/es/home/ourperspective/ourperspectivearticles/20 13/09/19/no-democracy-without-diversity-heba-el-kholy.html

Lipovetsky, Gilles. (2020). "La seducción se ha convertido en el motor del mundo",Periodico La vanguardia de España, sección cultura, 09/11/2020 extraído de https://www.lavanguardia.com/cultura/20201109/49339247184/la-seduccion-se-haconvertido-en-el-motor-del-mundo.html

Malik, Kenan. (2017) Aferrarse a la diversidad, apropiarse de la democracia. Revista Letras Libres. No 223/07/2017, México, (s/p). Extraído de https://www.letraslibres.com/espana-mexico/revista/aferrarse-la-diversidadapropiarse-la-democracia

Martín Frías, Jorge. (2020) No salimos a dar la batalla, salimos a ganar la guerra cultural. Fundación Disenso, Publicaciones de Sala de Prensa, extraída de https://fundaciondisenso.org/2020/11/03/jorge-martin-frias-no-salimos-a-dar-labatalla-salimos-a-ganar-la-guerra-cultural/

Pérez Lara, Alberto, (2000). El nuevo sujeto histórico frente a los desafíos de la emancipación en América Latina. en http://biblioteca.filosofia.cu/php/export.php?format=htm\&id=62\&view=1

Salazar, Robinson. (2003). Partidos Políticos Modulares. Un Recurso para América Latina. Revista de Ciencias Sociales Convergencia, Año 10, No 32, mayo-agosto. (Pp. 223-253). Disponible en: https://convergencia.uaemex.mx/article/view/1626/1235 